\title{
Fecal microbiota profile in atopic asthmatic adult patients
}

\author{
${ }^{1}$ Department of allergy and clinical immunology, Faculty of medicine, Ain Shams University, Cairo, Egypt
}

${ }^{2}$ Department of clinical pathology, Faculty of medicine, Ain Shams University, Cairo, Egypt

\section{KEY WORDS}

atopic asthma; density; diversity; gut microbiota; semi-quantitative stool culture

\author{
Corresponding author \\ Asmaa Saber Abdel-Rehim \\ Khalifa El-Maamon st, Abbasiya sq., \\ 11566 Cairo, Egypt \\ Phone: +20201006396955 \\ E-mail: acyyyy2@yahoo.com \\ Doi \\ 10.23822/EurAnnACI.1764-1489.48
}

\begin{abstract}
Summary
Background. Studies proposed a link between gut microbiota and airway tract. Objective. Study the diversity and density of gut microbiota in healthy and asthmatic patients. Method. Semi-quantitative stool cultures were performed from fecal samples collected from 80 adult asthmatic patients and 40 healthy individuals. Data on gender, age, dietetic history, clinical examination and investigations as skin prick test and pulmonary function testing were also collected. Results. Lactobacilli were found to be higher among patient group than control group. E. coli density was statistically higher in patient than control group. No significant difference was detected between male and female patients or controls. Lactobacilli were statistically more prevalent in stool culture of male cases than that of male controls. No difference was found between female cases and controls. There was no relationship between type of microbial growth and disease related parameters including age, duration of illness, number of allergens and pulmonary function test in cases. Conclusion. Atopic asthma is significantly associated with gut microbiota Lactobacilli and $\mathrm{E}$. coli. It is important to determine the organism involved to focus on microbiome-driven disease and therapies.
\end{abstract}

\section{Introduction}

Asthma is a complex disease that has influence on and is influenced by a colonization of the communities of microbes in the gut and the respiratory tract. These communities, in turn, are affected by environmental factors such as diet and antimicrobial administration in early life. Many of the animal studies proved the presence of a gut-airway axis. This opened up opportunities and ideas that aim at modifying the airway and/or gut microbiome in order to provide a novel strategy for prevention and treatment of allergic asthma (1).

Although more than 1000 different bacterial species represent human gut microbiota, only $150-170$ predominate in any given subject $(2,3)$. Infants during vaginal delivery are exposed to a population of microbes from the surrounding environment leading to formation of a colony of microbes in the human gut immedi- ately at birth. As time passes, the gut flora of infants transforms into another form that is reported in young adults (4).

Fermentation of non-digestible dietary residue and control of intestinal epithelial cell growth maturation are some of the functions of the microbiota that are important for maintaining balance of the immune system $(5,6)$. Yet, the human bacterial ecology has also been linked to pathogenesis and onset of many diseases, autoimmune disorders in particular, and of course allergy. These disorders, in return, cause further transformation and changes in the human microbiome (7-10). Therefore, biodiversity proves to be important in determining the wellbeing of human livelihood (11). This led to increasing interest in relationship between host and microbiota (12-14).

The relationship between allergic disease and gut microbiota was identified in several clinical studies. These studies reported a difference in the composition (diversity) of the bacterial mi- 
crobiome in the feces (15-21). Differences in the gut microbiota diversity involve Clostridium, Bacteroides, Bifidobacterium, Lactobacillus and Enterobacteriaceae (22). One study reported that allergic children had fewer Lactobacilli and Bacteroides species, but higher aerobic bacteria, especially Enterobacteriaceae and Staphylococci (23). Collectively, studies on gut and environmental microbiota concluded that negative balance occurs due to decreased exposure to a certain diversity of microbes leading to increased risk of allergy in general and asthma in particular $(24,25)$.

However, the scientific information about the relationship between allergy and gut microbiota dysbiosis is still controversial (26).

In asthma, no single straightforward mechanism can explain the gender differences amongst asthmatic subjects. Before puberty, it is more prevalent in boys than in girls; by adulthood, though, it is more prevalent in women than in men (27). Although several studies investigated microbiome in children (28-30), little is known about the complete microbiota profile of adult individuals suffering from asthma and relation to gender. Therefore, the aim of this work was to study the diversity of gut microbiota among atopic asthmatic adult males and females in comparison to matched controls, especially Enterobacteriaceae, Staphylococci and Lactobacilli.

\section{Methods}

This cross-sectional study included 120 adults; 80 of them were participants diagnosed with bronchial asthma according to Global Initiative for Asthma (GINA), 2015 (31). Cases were between the ages of 18 to 45 years, and were recruited from the Allergy Clinic of Ain Shams University over an eight-month period. The remaining forty adults were healthy individuals (controls). Exclusion criteria for standard analysis of gut flora (32) included adults $<18$ years old, abnormal body mass index, unusual dietetic regimen, smokers, history of cancer colon, autoimmune diseases, presence of inflammatory bowel disease, an acute or chronic diarrhea in the previous 4 weeks before taking the stool sample, antibiotic, prebiotic and probiotic or vitamin administration of a period less than one month before fecal sampling. Participants who received immunosuppressive therapy and/or allergen specific immunotherapy in the last 5 years, and patients on oral glucocorticoid treatment during the 6 months prior to the sample collection date were also excluded from the study, as well as patients with any associated co-morbidities.

Cases and controls were evenly stratified by gender; into 40 atopic asthmatic females and 40 atopic asthmatic males, and controls into 20 females and 20 males. An informed consent was obtained from all participants, and the study was approved by the Research Ethics Committee of Ain Shams University.

Cases completed a questionnaire on asthma symptoms $(33,34)$, triggering factors, and associated atopic diseases. Skin prick test (SPT) to allergens was used to determine atopic status. The most commonly inhaled allergens included mites, mixed pollen, mold, and animal epithelia. Positive $(0.1 \%$ histamine in phosphate-buffered saline) and negative (physiologic saline) controls were used. A wheal size over 3 millimeters greater than the negative control after 15 minutes was considered a positive result (35). Spirometry was performed at the Pulmonary Functions Laboratory at Ain Shams University Hospital using the Flow Mate V Plus Spirometer (Spirometrics, ME, USA). Reference values used were adapted from the European Respiratory Society (36).

\section{Stool sample collection}

A single fresh stool sample was collected from each participant in sterile screw caped containers and rapidly delivered to the Central microbiology laboratory of Ain Shams University Hospitals for culture, according to Infectious Diseases Society of America (IDSA) guidelines, 2013 (37).

\section{Semi quantitative stool culture}

Fecal specimens were examined to demonstrate the fecal microbial diversity of normal intestinal flora among the cases and controls. Semi quantitative stool cultures were performed using the quadrant technique. The quadrant technique is recommended for samples that are rich in microflora and contain numerous colony-forming units, such as stool or sputum. Use of this technique allows for enhanced separation and enumeration of colonies. Part of the stool were cultured directly on MacConkey agar media plates (Oxoid, UK); to identify the microbial growth pattern of gram negative bacteria, on Xylose lysine deoxycholate (XLD) agar media plates (Oxoid, UK) to exclude Shigella and carrier state of Salmonella, on blood agar plates aerobic and anaerobic (Oxoid, UK) for isolation of gram positive and anaerobic bacteria respectively, and on Man-Rogoza Sharp agar media (MRs) (Oxoid, UK) for isolation of Lactobacillus species.

Feces were inoculated by dipping a swab into the specimen. After implantation of the inoculum, a wire loop was flamed and cooled. The loop was held between the thumb and index finger and passed at a 90 degree angle several times through the initial inoculum into the second quadrant of the plate (streak area 1). The plate was turned 90 degrees, and the process was repeated, streaking into the third quadrant (streak area 2), and finally, after another 90 degree turn, into the fourth quadrant (streak area 3). The loop was flamed between quadrants. When streak plates were used, the relative numbers of bacteria was reported. Several methods of semi-quantitation were used. Bacterial density was measured by use of (very few, few, moderate or many) growth with the use of $(1+$ to $4+)$ growth scoring criteria, heavy growth had a score 3 or 4 (38).

Man-Rogoza Sharp agar media (MRs) (Oxoid, UK) for isolation of Lactobacillus species was incubated anaerobically for 72-hours 
in anaerobic conditions using (GasPak EZ Anaerobe, Becton Dickinson, Heidelberg, Germany) at $37^{\circ} \mathrm{C}$ in jars (AnaeroPack, Mitsubishi Gas Chemical America Inc., NewYork, NY, USA), other plates were incubated aerobically for 48 -hours at $37^{\circ} \mathrm{C}$. Colonies of different morphology grew and were identified according to standard phenotypic methods, as regards gram stain, colony morphology and biochemical reactions using Vitek 2 identification cards (39).

\section{Fecal flora richness (alpha diversity)}

We examined allergy associations with the number of observed species (richness) or alpha diversity of taxa with relative abundances.

\section{Fecal flora Composition and density (beta diversity)}

We studied the microbiome composition difference between patients and controls expressed by percentage of prevalence and density (colonization rate) which was expressed as the odds ratio (OR) and 95\% confidence interval (CI). The associations were adjusted for sex, age, body mass index, time since last antibiotic use, probiotic and vitamin use.

\section{Statistical methodology}

Comparative analysis was performed using student $\mathrm{t}$ test, Chisquared, and Fisher's exact test for continuous and categorical data, respectively. Continuous data was expressed as mean \pm standard deviation, while categorical data was expressed as number and percent of total. An odds ratio (OR) is a measure of association between an exposure and an outcome. The OR represents the odds that an outcome will occur given a particular exposure, compared to the odds of the outcome occurring in the absence of the exposure. The $95 \%$ confidence interval (CI) was used to estimate the precision of the OR. A p value of $p \leq$ 0.05 was considered statistically significant. Data analysis was completed using PASW Statistics, version 18.

\section{Results}

Eighty participants diagnosed with bronchial asthma were included, together with forty healthy individuals as a control group. Table 1 represents the demographic data between both studied groups, in which cases and controls were comparable as regards age and gender. There was no statistically significant difference between male and female atopic subjects as regards age, duration of illness, number of allergens and pulmonary function test.

As regards severity of bronchial asthma (interpretation of pulmonary function test), no statistically significant difference was found between male and female atopic subjects.

Regarding diversity and density of gut microbiota, Lactobacil$l i$ were found to be higher among patient group than control group with odds ratio $7.2(1.6-32.4) \mathrm{CI}$ (p value 0.01$)$. At the same time, Escherichia coli density (heavy colonization) was statistically higher in patients than control group with Odds ratio 16.9 (5.75-50) CI (P value < 0.001). However, no significant difference was detected between male and female patients or controls (table 2).

On comparing male cases with male controls, and female cases with female controls, Lactobacilli were statistically more prevalent in stool culture of male cases than in male controls ( $\mathrm{p}$ value $=0.045)$. On the other hand, no difference was found between female cases and controls (table 3).

Lastly, no relationship was detected between type of microbial growth and disease related parameters including age, duration

Table 1 - Demographics.

\begin{tabular}{|c|c|c|c|c|c|c|c|c|c|c|}
\hline & \multicolumn{10}{|c|}{ Groups } \\
\hline & \multicolumn{5}{|c|}{ cases } & \multicolumn{5}{|c|}{ control } \\
\hline & \multicolumn{4}{|c|}{ gender } & \multirow{3}{*}{$p$ value } & \multicolumn{4}{|c|}{ gender } & \multirow{3}{*}{ p value } \\
\hline & \multicolumn{2}{|c|}{$f(40)$} & \multicolumn{2}{|c|}{ m (40) } & & \multicolumn{2}{|c|}{$\mathbf{f}(20)$} & \multicolumn{2}{|c|}{ m (20) } & \\
\hline & mean & SD & mean & SD & & mean & SD & mean & SD & \\
\hline age & 31.85 & 8.37 & 29.70 & 8.72 & 0.264 & 34.90 & 7.58 & 31.10 & 11.35 & 0.390 \\
\hline duration of illness & 6.21 & 5.15 & 6.93 & 4.61 & 0.516 & & & & & \\
\hline number of allergens & 3.55 & 1.34 & 3.95 & 1.45 & 0.204 & - & - & - & - & - \\
\hline $\mathrm{FVC}^{1}$ & 74.60 & 20.15 & 75.30 & 20.24 & 0.877 & 87.46 & 15.77 & 87.51 & 13.46 & 0.994 \\
\hline $\mathrm{FEV}^{2}{ }^{2}$ & 73.06 & 20.27 & 71.45 & 20.65 & 0.726 & 88.96 & 12.08 & 91.76 & 10.20 & 0.582 \\
\hline FEV1/FVC & 90.90 & 11.58 & 92.02 & 14.14 & 0.70 & 97.55 & 11.45 & 99.27 & 12.99 & 0.757 \\
\hline
\end{tabular}


Table 2 - Distribution and density of isolated finding microbiota across the male and female in each group.

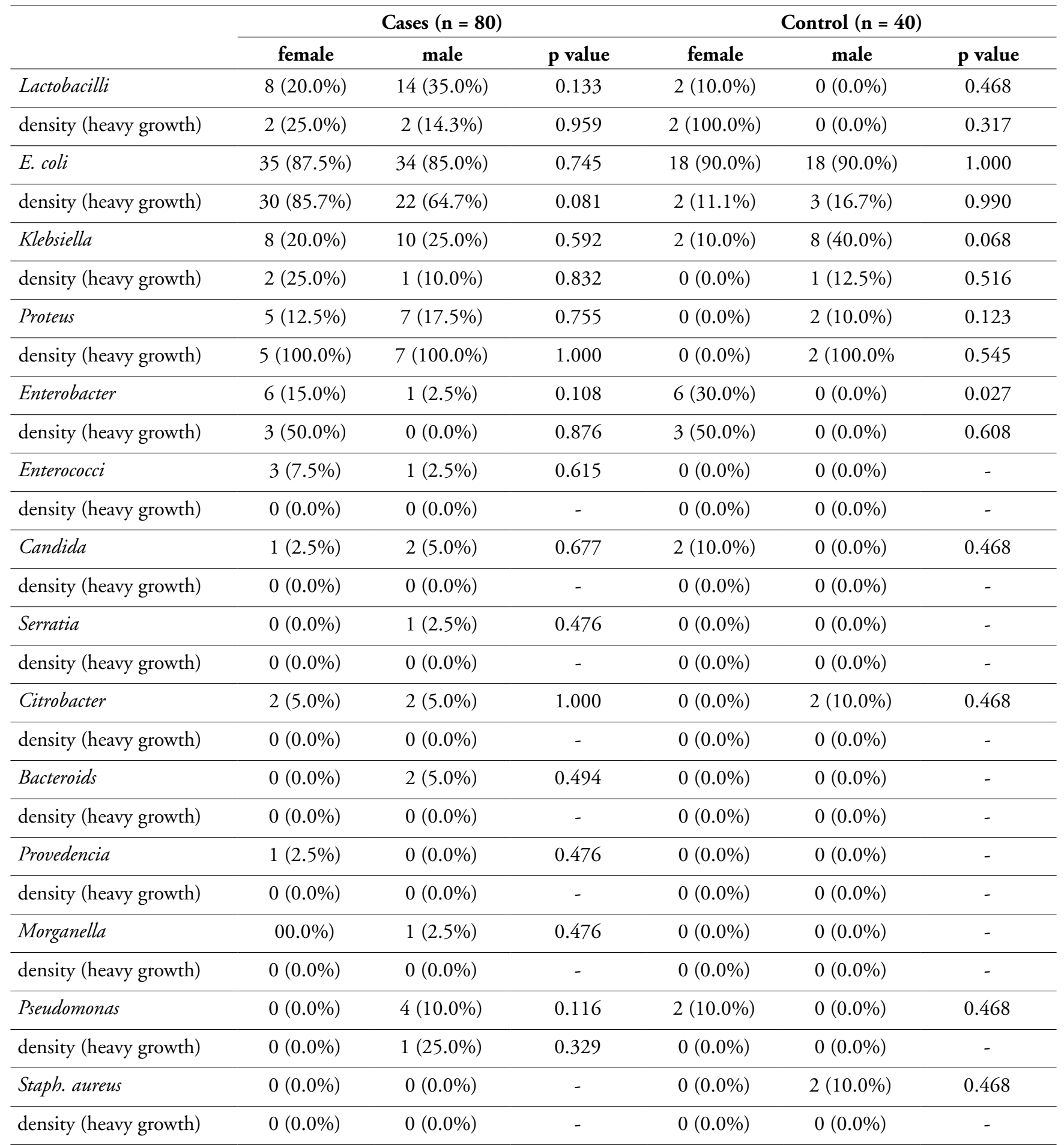

${ }^{1} \mathrm{FVC}$ : forced vital capacity; ${ }^{2} \mathrm{FEV} 1$ : forced expiratory volume during first second. 
Table 3 - Comparison of the distribution of isolated microbiota between cases and controls, stratified by gender.

\begin{tabular}{lcccccc}
\hline & \multicolumn{3}{c}{ Female } & \multicolumn{2}{c}{ Male } \\
\cline { 2 - 7 } & cases & control & p value & cases & control & p value \\
\hline Lactobacilli & $8(20 \%)$ & $2(10 \%)$ & 0.665 & $14(35 \%)$ & 0 & 0.045 \\
\hline E. coli & $35(87.5 \%)$ & $18(90 \%)$ & 1 & $34(86 \%)$ & $18(90 \%)$ & 1 \\
\hline Klebsiella & $8(20 \%)$ & $2(10 \%)$ & 0.665 & $10(25 \%)$ & $8(40 \%)$ & 0.436 \\
\hline Proteus & $5(12.5 \%)$ & 0 & 0.569 & $7(17.5 \%)$ & $2(10 \%)$ & 1 \\
\hline Enterobacter & $6(15 \%)$ & $6(30 \%)$ & 0.358 & $1(2.5 \%)$ & 0 & 1 \\
\hline Enterococci & $3(7.5 \%)$ & 0 & 1 & $1(2.5 \%)$ & 0 & 1 \\
\hline Candida & $1(2.5 \%)$ & $2(10 \%)$ & 0.363 & $2(2.5 \%)$ & 0 & 1 \\
\hline Serratia & 0 & 0 & 0 & $1(2.5 \%)$ & 0 & 1 \\
\hline Citrobacter & $2(5 \%)$ & 0 & 1 & $2(5 \%)$ & $2(10 \%)$ & 0.496 \\
\hline Bacteroids & 0 & 0 & 0 & $2(5 \%)$ & 0 & 1 \\
\hline Provedencia & $1(2.5 \%)$ & 0 & 1 & 0 & 0 & 0 \\
\hline Morganella & 0 & 0 & 0 & 1 & 0 & 1 \\
\hline Pseudomonas & 0 & $2(10 \%)$ & 0.2 & $4(10 \%)$ & 0 & 0.571 \\
\hline Staph. Aureus & 0 & 0 & 0 & 0 & $2(10 \%)$ & 0.2 \\
\hline
\end{tabular}

of illness, number of allergens and pulmonary function test in atopic patients.

\section{Discussion}

Competent immune system depends on T-helper (Th) CD4 lymphocyte population balance. The onset of allergic disease is due to an imbalance in this population and favoring immunity towards Th2 (40). Gut microbiota participates crucially in the evolution of the intestinal immune system as well as adjustment of the T helper cell balance. Moreover, the loss of biodiversity may have serious impact on human wellbeing (41). Studies showed that the risk of developing asthma and allergy happens due to change in diversity of the body's microbiota $(42,43)$. This may explain why diseases such as asthma and allergy develop at any age. Also evidence showed that there is an increased incidence of asthma and allergies in industrialized countries during the last 50 years. Moreover, studies demonstrated correlation between allergic diseases and antibiotic use (44), altered fecal microbiota (45), and dietary changes (46). Some studies even suggest an association between growing up in a farm environment, early life consumption of unpasteurized milk, and decreased risk of developing allergy later in life (47-49). All the previous support the microbial hypothesis that proposed that microbiota is vital for immune hemostasis.
It is well known that the dendritic cells (DCs) are the antigen-presenting cells responsible for the activation of naive $T$ cells. DC recognizes microbes in the intestine, samples them directly either from the lumen or through the gut-associated lymphoid tissue (GALT), then activates a cascade of events eventually ending in the differentiation of Th1, Th2, and Treg cells. (40). If dysbiosis prevails, increased susceptibility to airway colonization by certain bacteria or the microbiota may occur, resulting in switching immunity towards the inflammatory immune responses (50).

To the best of our knowledge, few studies investigated diversity of microbiota in adult atopic subjects. Most of the studies conducted before, focused on atopic children.

Several studies suggest a role for sex hormones in the pathogenesis of asthma. Asthma prevalence was found to be higher in women than men, as recorded by Rhodes and co-workers. On the other hand, other clinical studies pointed to distinctive changes in the prevalence and severity of asthma with age progression (51-55). The current study focused on adult asthmatic subjects and investigated the diversity of microbiota in males and females. The design of this study was done to eliminate the hormonal factor by dividing both subgroups equally into male and female group. In our study, although diversity of bacteria was detected to be more towards Klebsiella, Proteus, Enterobacter, Enterococci in asthmatics, the results did not reach statistical significance dif- 
ference except for predominance of Lactobacilli among patient group than in control group. At the same time, E. coli density (heavy colonization) was statistically higher in patients than in control group. However, no significant difference was detected between male and female patients. On comparing male cases with male controls and female cases with female controls, Lactobacilli were statistically more prevalent in stool culture of male cases than in male controls. On the other hand, no difference was found between female cases and controls.

Penders and co-workers reported that gut microbial differences contribute to allergy risk in humans (56). In two studies, infants who had a higher fecal abundance of Clostridium difficile had an increased risk of developing an allergy in the future $(9,57)$. The current study showed low isolation rate of Bacteroides and no growth of Bifidobacterium in the conducted stool cultures as well as other species. This may return to the fact that there is pediatric age predominance of some strains as Bifidobacterium. The number of Bifidobacteria actually declines in the human body with age. In infants who are breast-fed, Bifidobacteria constitute about $90 \%$ of intestinal bacteria; however, this number is lower in bottle-fed infants and adults (58).

The diversity of the microbiota in healthy and allergic children was studied in two-year old children in Sweden and Estonia countries. Allergic children showed few colonies of Lactobacilli and Bacteroids and had higher counts of aerobic bacteria, especially Enterobacteriaceae and Staphylococci, irrespective of country of residence (23). Differences of the gut microbiota diversity between allergic and healthy children was also demonstrated by another case control study, but the differences identified concerned various particular genera and species, including Bifidobacterium, Clostridium, Bacteroides, Lactobacillus and Enterobacteriaceae (22). This is in accordance to our study, in which there was not only higher isolation of Lactobacilli in asthmatic patients, but also higher growth of Lactobacillus in male patients than male controls. E. coli density (heavy colonization) was statistically higher in patients than in control group. At the same time, the prevalence of $E$. coli as one of Enterobacteriaceae was more detected in asthmatic patients than control in a study by Bjorksten and co-workers (22). Enterobacteriaceae and Staphylococci were suggested by Penders et al. as potential candidates, as these have been associated with an increased risk of atopic diseases (10). This study detected Staph. aureus in 2 of control subjects only. Still, results were of no statistical significant difference.

Reduction of Bacteroidetes, Lactobacilli and Bifidobacteria were found in a study by Ouwehallnd et al. They demonstrated that this finding has been associated with an asthma phenotype (59). However, another study by Waligora-Dupriet and colleagues found that the prevalence of Bifidobacterium was similar in healthy and allergic subjects, regardless of the type of the allergic disease (58). On the other hand, Sjogren and colleagues recorded that Bacteroides colonization of the gut was not found to be related to allergy (17). Similarly, the present study showed growth of Bacteroids only in two male cases, yet no statistical significant value related was found.

Rook and co-workers established that Lactobacilli are microorganisms that stimulate immune regulation by triggering regulatory T-cell responses (60). However, He et al. suggested that Bifidobacteria was similar to Lactobacilli in their effects, and that the immune system may be species dependent because intestinal Bifidobacterium species showed to induce varying cytokine production by cells of the innate immune system (61). On the other hand, another study by Stsepetova et al. showed that allergy is related to restricted Bifidobacterium diversity (62). Bottcher and co-workers suggested an association between allergy and Clostridium difficile as they found that allergic infants had higher fecal concentrations of the rarely detected icaproic acid, which has been associated with the presence of Clostridium difficile (45), and Woodcock et al. detected higher $C$. difficile IgG antibody levels in allergic than non-allergic subjects (63). The present study could not prove presence or detect Clostridium difficile in neither case or control subject, because Clostridium is one of fecal flora characterized by attachment to mucosal surface of intestine rendering the culture and isolation very difficult (64). Furthermore, Kalliomaki et al. detected a reduced ratio of Bifidobacteria to Clostridia in the stools of atopic subjects in comparison to those of non-atopic subjects (57).

In contrast to the current study, Hevia and colleagues showed that the microbial alpha-diversity was not significantly different between healthy and allergic adult individuals. However, the analysis of specific bacterial groups detected significantly lower levels of Bifidobacteria in patients with long-term asthma. Also, in allergic individuals the Bifidobacterium adolescentis species prevailed within the bifidobacterial population (65). This in line with Hua and co-workers, who found statistically significant fecal dysbiosis across multiple allergies in adult allergic patients. Specifically, reduced richness and altered composition was found with all allergies except asthma, bee sting, and eczema. The dysbiosis was most marked with allergies to nuts and seasonal pollen, and it was driven by higher abundance of Bacteroidales and reduced abundance of Clostridiales (66).

\section{Conclusions}

The current challenge aimed to identify the role of gut microbiota in allergic disease, specifically atopic asthma, in adults. In addition, the study investigated the relationship between gender and gut microbiota profile. This study demonstrated predominance of Lactobacilli and E. coli in patients group. Interestingly, the study demonstrated higher levels of Lactobacillus in male patients. Yet, there was no relationship between type of microbial growth in stool culture of cases and parameters of the disease including age, duration of illness, number of allergens and pulmonary function test. 
Further investigations are required, especially new methods like quantitative polymerase chain reaction, to investigate a relationship and detect whether microbiota could be considered an additional factor in pathogenesis of asthma. Proving this link may lead to new opportunities in diagnostic and therapeutic modalities. Further studies may be needed on large scale for evaluation of gut microbiota in asthmatic subjects using molecular methods to identify strains at the species level, evaluation of significance of certain strains, and probiotics as an adjuvant treatment of bronchial asthma. Evaluation of hormonal and genetic factors in comparison with microbiota would be preferable. Future research should include patients from other hospitals, from other areas, other countries and other races.

\section{Conflict of interest}

The authors declare that they have no conflict of interest.

\section{References}

1. Kei E, Susan V. Microbiota in Allergy and Asthma and the Emerging Relationship with the Gut Microbiome. Cell Host Microbe 2015; 17(5)592-602.

2. O'Hara AM, Shanahan F. The gut flora as a forgotten organ. EMBO Rep 2006; 7688-93.

3. Willey J, Sherwood L, Woolverton C. Prescott's Microbiology (9th ed). New York: McGraw Hill. 2013; 713-21.

4. Huurre A, Kalliomaki M, Rautava S, Rinne M, Salminen S, Isolauri E. Mode of delivery: effects on gut microbiota and humoral immunity. Neonatology 2008; 93:236-40.

5. Guarner F, Malagelada JR. Gut flora in health and disease. Lancet 2003; 361:512-9.

6. Kau AL, Ahern PP, Griffin NW, Goodman AL, Gordon JI. Human nutrition, the gut microbiome, and immune system: envisioning the future. Nature 2011; 474(7351)327-36.

7. Kobayashi T, Okamoto S, Hisamatsu T, Kamada N, Chinen $\mathrm{H}$, Saito R, et al. IL23 differentially regulates the Th1/Th17 balance in ulcerative colitis and Crohn's disease. Gut 2008; 57(12):1682-9.

8. Chow J, Mazmanian SK. Getting the bugs out of the immune system: do bacterial microbiota "fix" intestinal T cell responses? Cell Host Microbe 2009; 5(1):8-12.

9. Penders J, Stobberingh EE, van den Brandt PA, Thijs C. The role of the intestinal microbiota in the development of atopic disorders. Allergy 2007; 62 (11):1223-36.

10. Penders J, Thijs C, van den Brandt PA, Kummeling I, Snijders $\mathrm{B}$, et al. Gut microbiota composition and development of atopic manifestations in infancy: the KOALA Birth Cohort Study. Gut 2007; 56 (5):661-7.

11. Sen T, Samanta SK. Medicinal plants, human health and biodiversity: a broad review. Adv Biochem Eng Biotechnol 2015; 147:59-110

12. June L. The gut microbiome shapes intestinal immune responses during health and disease. Nat Rev Immunol 2009; 9(5)313-23.

13. Qin J, Li R, Raes J, Arumugam M, Burgdorf KS, Manichanh C, Nielsen T, et al. A human gut microbial gene catalogue established by metagenomic sequencing. Nature 2010; 464(7285):59-65.

14. Human Microbiome Project Consortium. Structure, function and diversity of the healthy human microbiome. Nature 2012; 486(7402):207-14.

15. Wang M, Karlsson C, Olsson C, Adlerberth I, Wold AE, Strachan DP, et al. Reduced diversity in the early fecal microbiota of infants with atopic eczema. J Allergy Clin Immunol 2008; 121:129-34

16. Forno E, Onderdonk A, McCracken J, Litonjua A, Laskey D, Delaney $\mathrm{M}$, et al. Diversity of the gut microbiota and eczema in early life. Clin Mol Allergy 2008; 611.

17. Sjögren YM, Jenmalm MC, Böttcher MF, Björkstén B, Sverremark-Ekström E. Altered early infant gut microbiota in children developing allergy up to 5 years of age. Clin Exp Allergy 2009; 39:518-26.

18. Bisgaard H, Li N, Bonnelykke K, Chawes BL, Skov T, Paludan-Muller G, et al. Reduced diversity of the intestinal microbiota during infancy is associated with increased risk of allergic disease at school age. J Allergy Clin Immunol 2011; 128:646-52.

19. Abrahamsson TR, Jakobsson HE, Andersson AF, Björkstén B, Engstrand L, Jenmalm MC. Low diversity of the gut microbiota in infants with atopic eczema. J Allergy Clin Immunol 2012; 129:434-40.

20. Ismail IH, Oppedisano F, Joseph SJ, Boyle RJ, Licciardi PV, Robins-Browne RM, et al. Reduced gut microbial diversity in early life is associated with later development of eczema but not atopy in high-risk infants. Pediatr Allergy Immunol 2012; 23:674-81.

21. Penders J, Gerhold K, Stobberingh EE, Thijs C, Zimmermann K, Lau S, et al. Establishment of the intestinal microbiota and its role for atopic dermatitis in early childhood. J Allergy Clin Immunol 2013; 132:601-7.

22. Bjorksten B, Sepp E, Julge K, Voor T and Mikelsaar M. Allergy development and the intestinal microflora during the first year of life. J Allergy Clin Immunol 2001; 108:516-20.

23. Bjorksten, B., Naaber, P., Sepp, E., and Mikelsaar, M. The intestinal microflora in allergic Estonian and Swedish 2-year-old children. Clin Exp Allergy 1999; 29:342-6.

24. Kozyrskyj AL, Bahreinian S, Azad MB. Early life exposures: impact on asthma and allergic disease. Curr Opin Allergy Clin Immunol 2011; 11(5):400-6.

25. McLoughlin RM, Mills KH, Influence of gastrointestinal commensal bacteria on the immune responses that mediate allergy and asthma. J Allergy Clin Immunol 2011; 127:1097-107.

26. Nylund L, Nermes M, Isolauri E, Salminen S, de Vos WM, Satokari R. Severity of atopic disease inversely correlates with intestinal microbiota diversity and butyrate-producing bacteria. Allergy 2015; 70:241-4.

27. Postma DS. Gender differences in asthma development and progression, Gend Med 2007; 4:133-46.

28. Sandberg M, Frykman A, Ernerudh J, Berg G, Matthiesen L, Ekerfelt $\mathrm{C}$, et al. Cord blood cytokines and chemokines and development of allergic disease. Pediatr Allergy Immunol 2009; 20:519-27.

29. Abelius MS, Ernerudh J, Berg G, Matthiesen L, Nilsson LJ, Jenmalm MC. High cord blood levels of the T-helper 2-associated chemokines CCL17 and CCL22 precede allergy development during the first 6 years of life. Pediatr Res 2011; 70:495-500.

30. Jenmalm MC. Childhood immune maturation and allergy development: regulation by maternal immunity and microbial exposure. Am J Reprod Immunol 2011; 66:75-80.

31. Global strategy for asthma management and prevention. Global Initiative for Asthma (GINA). 2015. Available from: http://www. ginasthma.org. 
32. Million M, Angelakis E, Maraninchi M, M, R, R, et al. Correlation between body mass index and gut concentrations of Lactobacillus reuteri, Bifidobacterium animalis, Methanobrevibacter smithii and Escherichia coli. International Journal of Obesity 2013; 37(11):1460-6.

33. Thomas M, Kay S, Pike J, Williams A, Rosenzweig JR, Hillyer EV, et al. The Asthma Control Test (ACT) as a predictor of GINA guideline-defined asthma control: analysis of a multinational cross-sectional survey. Prim Care Respir J 2009; 18:41-9.

34. Hanlon J, Watson ME, Jhingran P. The minimally important difference of the Asthma Control Test. J Allergy Clin Immunol 2009; 124:719-23.

35. Berger A. Skin prick testing. BMJ 2002; 24,325(7361):414.

36. Quanjer PH, Tammeling GJ, Cotes JE, Pedersen OF, Peslin R and Yernault JC. Lung volumes and forced ventilatory flows. Report Working Party Standardization of Lung Function Tests, European Community for Steel and Coal. Official Statement of the European Respiratory Society. Eur Respir J Suppl 1993; 16:5-40.

37. Baron EJ , Miller JM, Weinstein MP, Richter SS, Gilligan PH, et al. IDSA guidelines a guide to utilization of microbiology laboratory for diagnosis of infectious diseases, clinical infectious advance access published July 2013; 10:1-100

38. College of Physicians and Surgeons of Saskatchewan Laboratory Quality Assurance Program. Procedures / Guidelines for the Microbiology Laboratory, Bacteriology Culture Planting Procedures: 2010; 12-4.

39. Mahon CR and Manuselis G. Textbook of Diagnostic Microbiology, $4^{\text {th }}$ edition, Chapter 6. W.B. Saunders, 2010; 978,4160,6165-66.

40. Rautava, S, Ruuskanen O, Ouwehand A, Salminen S, Isolauri E. The hygiene hypothesis of atopic disease? An extended version. J Pediatr Gastroenterol Nutr 2004; 38:378-88.

41. Butkus M. All health is local: biodiversity, ethics, and human health. Ethics Policy Environ 2015; 18(1):1-15.

42. Chen Y, Blaser MJ. Helicobacter pylori colonization is inversely associated with childhood asthma. J Infect Dis 2008; 198 (4):553-60.

43. Haahtela T, Holgate S, Pawankar R, Akdis CA, Benjaponpitak S, Caraballo L, et al. The biodiversity hypothesis and allergic disease: world allergy organization position statement. World Allergy Org J 2013; 6(1):3. doi:10.1186/1939-4551-6-3.

44. McKeever TM, Lewis SA, Smith C, Collins J, Heatlie H, Frischer $\mathrm{M}$, et al. Early exposure to infections and antibiotics and the incidence of allergic disease: a birth cohort study with the West Midlands General Practice Research Database. J Allergy Clin Immunol 2002; 109(1):43-50.

45. Bottcher MF, Nordin EK, Sandin A, Midtvedt T, Bjorksten B. Microflora associated characteristics in faeces from allergic and nonallergic infants. Clin Immunol 2000; 30(11):1590-6.

46. Julia V, Macia L, Dombrowicz D. The impact of diet on asthma and allergic diseases. Nat Rev Immunol 2015; 15(5):308-22.

47. Blümer N, Sel S, Virna S, Patrascan CC, Zimmermann S, Herz $\mathrm{U}$, et al. Perinatal maternal application of Lactobacillus rhamnosus GG suppresses allergic airway inflammation in mouse offspring. Clin Exp Allergy 2007; 37:348-57.

48. Riedler J, Braun-Fahrländer C, Eder W, Schreuer M, Waser M, Maisch S, et al. Exposure to farming in early life and development of asthma and allergy: a cross-sectional survey. Lancet 2001; 358,11:29-33

49. Ege, M. J. Frei R, Bieli C, Schram-Bijkerk D, Waser M, Benz $\mathrm{MR}$, et al. Not all farming environments protect against the devel- opment of asthma and wheeze in children. J Allergy Clin Immunol 2007; 119:1140-7.

50. Salami O, Marsland B. Has the airway microbiome been overlooked in respiratory disease? Genome Medicine 2015;762.

51. Becklake MR, Kauffmann F. Gender differences in airway behaviour over the human life span. Thorax 1999; 54(12):1119-38.

52. Rhodes L, and Redd C. Sex differences in asthma prevalence and other disease characteristics in eight states. J Asthma 2005; 42:777-82.

53. Melgert BN, Ray A, Hylkema MN, Timens W, Postma DS. Are there reasons why adult asthma is more common in females? Curr Allergy Asthma Rep 2007; 7(2):143-50.

54. Almqvist C, Worm M, Leynaert B; working group of GA2LEN WP 2.5. Gender Impact of gender on asthma in childhood and adolescence: a GA2LEN review. Allergy 2008; 63(1):47-57.

55. Vink NM, Postma DS, Schouten JP, Rosmalen JG, Boezen HM. Gender differences in asthma development and remission during transition through puberty: the Tracking Adolescents' Individual Lives Survey (TRAILS) study. J Allergy Clin Immunol 2010; 126(3):498-504.

56. Penders J, Gerhold K, Thijs C, Zimmermann K, U, Lau S, et al. New insights into the hygiene hypothesis in allergic diseases. Gut Microbes 2014; 5(2)239-44.

57. Kalliomaki M, Kirjavainen P, Eerola E, Kero P, Salminen S, Isolauri E. Distinct patterns of neonatal gut microflora in infants in whom atopy was and was not developing. J Allergy Clin Immunol. 2001; 107:129-34.

58. Waligora-Dupriet AJ, Campeotto F, Romero K, Mangin I, Rouzaud G, Menard O, et al. Diversity of gut Bifidobacterium species is not altered between allergic and non-allergic French infants. Anaerobe 2001; 17:91-6.

59. Ouwehand AC, Isolauri E, He F, Hashimoto H, Benno Y, Salminen S. Differences in Bifidobacterium flora composition in allergic and healthy infants. J Allergy Clin Immunol 2001; 108:144-5.

60. Rook GA, Adams V, Hunt J, Palmer R, Martinelli R, Brunet LR. Mycobacteria and other environmental organisms as immunomodulators for immunoregulatory disorders. Springer Semin Immunopathol 2004; 25:237-5.

61. He F, Morita H, Hashimoto H, Hosoda M, Kurisaki JI, Ouwehand $\mathrm{AC}$, et al. Intestinal Bifidobacterium species induce varying cytokine production. J Allergy Clin Immunol 2002; 109:1035-6.

62. Stsepetova J, Sepp E, Julge K, Vaughan E, Mikelsaar M, De Vos WM. Molecularly assessed shifts of Bifidobacterium sp. and less diverse microbial communities are characteristic of 5-yearold allergic children. FEMS Immunol Med Microbiol 2007; 51:260-9.

63. Woodcock A, Moradi M, Smillie FI, Murray CS, Burnie JP, Custovic A. Clostridium difficile, atopy and wheeze during the first year of life. Pediatr Allergy Immunol 2002; 133:57-60.

64. 64. DuPont HL. Approach to the patient with suspected enteric infection. In: Goldman L, Schafer Al, eds. Goldman's Cecil Medicine. $24^{\text {th }}$ ed. Philadelphia, PA: Saunders. Elsevier: 2011; chap 291.

65. Hevia A, Milani C, López P, Donado CD, Cuervo A, González S, et al. Allergic Patients with Long-Term Asthma Display Low Levels of Bifidobacterium adolescentis. PLOS ONE |2016; DOI:10.1371/ journal.pone.0147809

66. Hua X, Goedert JJ, Pu A, Yu G, Shi J. Allergy associations with the adult fecal microbiota: Analysis of the American Gut Project. EBio Medicine 2016; 3:172-9. 